\title{
INCLUSÃO ESCOLAR DE ALUNOS PÚBLICO-ALVO DA EDUCAÇÃO ESPECIAL: COMO SE DÁ O TRABALHO PEDAGÓGICO DO PROFESSOR NO ENSINO FUNDAMENTAL I?
}

\section{INCLUSION OF SCHOOL STUDENTS TARGET OF SPECIAL EDUCATION: HOW IS THE PEDAGOGICAL WORK OF THE TEACHER IN ELEMENTARY SCHOOL?}

\author{
Suzana Sirlene da SILVA ${ }^{\mathrm{i}}$ \\ Relma Urel Carbone CARNEIRO ${ }^{\mathrm{ii}}$
}

RESUMO: O presente artigo relata uma pesquisa desenvolvida com professoras que trabalham em escolas comuns e que têm alunos com deficiência incluídos em sala de aula. A problemática central do estudo versa e tem por objetivo verificar como está se dando o trabalho docente/pedagógico com alunos público-alvo da educação especial em sala comum. Para isto, constituiu-se um estudo qualitativo de natureza exploratória e descritiva, utilizando como instrumento de coleta de dados um questionário livre e com questões abertas. As participantes foram cinco professoras de escolas públicas e privadas. Para analisar os dados foi utilizado Análise de Conteúdo e os resultados revelaram que as professoras são profissionais iniciantes, tendo professoras que dobram o período de trabalho, não apresentando cursos na área de educação especial; trabalham a partir da naturalização do aluno, com atividades adaptadas e diferenciadas, encontrando dificuldades na acessibilidade e na concentração desse aluno nas tarefas apresentadas, não consideram que há um trabalho colaborativo entre elas e as professoras especialistas, mas concordam que a inserção do aluno público-alvo da educação especial traz ganhos no contexto geral, sendo que é o docente a peça importante para a real inclusão acadêmica dos alunos em questão.

PALAVRAS-CHAVE: Educação especial. Inclusão escolar. Trabalho docente. Práticas pedagógicas.

ABSTRACT: This article reports a research developed with teachers working in mainstream schools and having students with disabilities included in the classroom. The central problem of the study versa and aims to verify how you are giving the teaching/ educational work with target group students of special education in the common room. For this, it constitutes a qualitative study of exploratory and descriptive, using as a data collection tool free questionnaire and open questions. Participants were five teachers from public and private schools. To analyze the data was used content analysis and the results revealed that the teachers are new professionals, and teachers plying the period of work, not presenting courses in the field of special education; work from the naturalization of the student, tailored and differentiated activities, encountering difficulties in accessibility and concentration of this student in the tasks presented, do not consider that there is a collaborative work between them and the specialist teachers, but agree that the inclusion of the target group of special education student brings gains in the overall context, and is teaching the important part for real academic inclusion of the pupils concerned.

KEYWORDS: Special education. School inclusion.teaching work . Pedagogical practices. 


\section{Introdução}

Tratados internacionais como a Declaração de Educação para Todos (Jontiem em 1990) e a Declaração de Salamanca (Espanha em 1994), trouxeram novas ideias para se pensar a escola como um local democrático, que acolhe todas as pessoas sem discriminações e de uma forma justa, eliminando os preconceitos e estereótipos da educação escolar. Cabe à educação básica ser o alicerce para a aprendizagem e desenvolvimento humano de todas as crianças, jovens e adultos.

A universalização do acesso e da equidade na educação, com concentração na aprendizagem, são focos relevantes da Declaração de Educação para todos, tendo como ponto importante a atenção especial ao atendimento das necessidades básicas de aprendizagem das pessoas com deficiências: "é preciso tomar medidas que garantam a igualdade de acesso à educação aos portadores de todo e qualquer tipo de deficiência, como parte integrante do sistema educativo" $(1998$, p. 4)

O princípio orientador das ações da Declaração de Salamanca (1994), consiste em afirmar que as escolas devem se ajustar a todos os alunos, independentemente das suas condições físicas, sociais, linguísticas e outras características consideradas diferentes, sendo que todas as crianças deverão ser incluídas nas escolas comuns.

As escolas devem se modificar e encontrar formas de educar com sucesso essas crianças e participar nas modificações das atitudes discriminatórias e na construção de sociedades acolhedoras e inclusivas onde se acentuem as potencialidades das pessoas com deficiências e ou impedimentos educacionais e, que a aprendizagem se adapte as necessidades desses alunos em vez de serem eles que devam se adaptar a concepções predeterminadas.

A inclusão escolar a partir dessas Declarações começou a ganhar forma e iniciou-se a disseminação de seus ideais em vários países. As reformas educacionais promovidas a partir da década de 1990, pelos organismos internacionais, cooperaram para que a inclusão fosse pensada como resposta para escolarizar alunos considerados diferentes em relação ao público-alvo comumente atendido na escola.

No Brasil, segundo Kassar (2011), a partir dessas duas conferências a "Educação Especial no país ganhou contorno de política pública", caracterizada pela mudança de sua trajetória anterior de integração ${ }^{1}$, caminhando em direção à inclusão escolar.

\footnotetext{
${ }^{1}$ Integração Escolar foi um movimento surgido na década de 1960 a 1970, relacionado à filosofia da normalização que tinha como pressuposto básico a ideia de que toda pessoa com deficiência teria o direito
} 
Conforme Baptista (2011, p.59), "nos últimos vinte anos temos vivenciado, no Brasil, um fortalecimento das propostas de inclusão escolar como organizadora das metas para a escolarização das pessoas com deficiência, transtornos globais e altas habilidades/superdotação";; assim, é necessário que as escolas se ajustem ao novo alunado.

Bürkle (2010, pág. 35) esclarece que a "inclusão escolar se refere a uma [concepção de] educação que tem como objetivo atender à diversidade de discentes, principalmente, aqueles que estiveram historicamente excluídos do espaço escolar". Ainda segundo Bürkle (opus cit) a Educação Inclusiva:

vem propor que todas as crianças independente do sexo, cultura, origem socioeconômica, características físicas, condições orgânicas, ou padrão de aprendizagem, estejam na escola, em classe comum, se beneficiando de um ensino de qualidade, atendendo ao princípio de Educação para Todos.

O governo federal, por meio das políticas públicas educacionais e seguindo tendências internacionais, promulgou vários documentos legais no país a partir das décadas de 1980 e 1990, estabelecendo o atual contexto da Educação Especial. Lembrando que Mazzotta (2011) relata que a trajetória da Educação Especial no país desenvolveu-se em dois períodos importantes, um onde teve iniciativas oficiais e particulares isoladas, outro onde começou a ter iniciativas oficiais de âmbito nacional quanto à educação da pessoa com deficiência.

A política em educação especial no Brasil manteve por muito tempo sua ênfase no atendimento segregado nas instituições especializadas particulares em detrimento do atendimento educacional nas escolas públicas. Porém, a partir do período de 1981-1988 começou-se a ter um pequeno aumento $(41,92 \%)$ de matrículas no Ensino Regular, comparado aos anos anteriores. (MAZZOTTA, 2011).

Os dados do Censo Escolar da Educação Básica 2013 - Resumo Técnico (2014, p. ) revelam que

os importantes avanços alcançados pela atual política são refletidos em números: $62,7 \%$ das matrículas da educação especial em 2007 estavam nas escolas públicas e 37,3\% nas escolas privadas. Em 2013, esses números alcançaram $78,8 \%$ nas públicas e $21,2 \%$ nas escolas privadas, mostrando a efetivação da educação inclusiva e o empenho das redes de

inalienável de experienciar um estilo ou padrão de vida que seria comum ou normal em sua cultura (MENDES, 2010). As escolas comuns passaram então a aceitar a ideia de incorporar crianças ou adolescentes com deficiência em classes regulares ou, pelo menos, em classes especiais ou de recursos, em ambientes menos segregados do que as instituições de caráter especializado (FONTES, 2009). 
ensino em envidar esforços para organizar uma política pública universal e acessível às pessoas com deficiência.

Com os novos direcionamentos da Política Nacional da Educação Especial na perspectiva de Educação Inclusiva (PNEE-EI 2008), várias mudanças ocorreram e têm possibilitado a participação de um número cada vez maior de pessoas público-alvo da educação especial na educação regular, sendo observada a expansão das matrículas nas escolas regulares para esses alunos, com um aumento expressivo entre 2007 e 2013 - de 654.606 passaram para 843.342 matrículas, segundo o censo escolar de 2013 - o que acarretou novas perspectivas e desafios para o contexto escolar brasileiro. Perspectivas, por estar abarcando uma população que tradicionalmente foi "educada" longe da escola comum, em centros e escolas/salas especializadas e desafios (dificuldades) por ainda não encontrar na educação regular respaldo quanto ao devido atendimento a esses alunos em seu desenvolvimento acadêmico.

Com o aumento de alunos com deficiência nas escolas regulares em sala comum, muitos professores não se sentem preparados para atender academicamente as especificidades que esses alunos apresentam, pois para muitos falta informação sobre as variadas deficiências e síndromes: falta também capacitação profissional, o que pode acarretar entraves para o desenvolvimento de um trabalho acadêmico de qualidade na escola que se diz para todos.

Para além das matrículas é fundamental pensar em estratégias que efetivem a permanência e participação dos alunos com deficiência nas atividades escolares, dado que apesar de ter muitas recomendações nos documentos legais referentes a Educação Especial/Inclusão Escolar, o professor na prática se vê cercado de incertezas, o que muitas vezes o impede de adotar uma didática diferenciada com vistas a empoderar o aluno com deficiência no seu aprendizado acadêmico. A partir desses dados, este trabalho se propôs a verificar e analisar como está se dando o trabalho pedagógico com alunos público-alvo da Educação Especial em sala de aula comum, na visão de alguns professores, para conhecimento do panorama da realidade do que se tem vivido quanto a inclusão acadêmica desses alunos.

\section{Método}


A abordagem metodológica utilizada na pesquisa é a qualitativa, de natureza exploratória e descritiva, viabilizada por questionário semiestruturado com questões abertas sobre a formação acadêmica e atuação de professoras regulares e sobre as percepções e concepções das mesmas quanto ao trabalho pedagógico realizado na inclusão escolar.

A escolha pela pesquisa qualitativa se firma, pois "são na sua maior parte dirigida para a descoberta, a identificação, a descrição aprofundada e a formação de explicações. Investigam o significado e a intencionalidade dos atos, das relações sociais e das estruturas sociais" (VILELAS, 2009, p. 107).

O instrumento de coleta de dados utilizado foi o questionário, sendo que a escolha dessa técnica se deve a exposição de Vilelas (2009, p. 269) que relata que a "finalidade de usar o questionário, é obter de maneira sistemática e ordenada a informação acerca da população que se estuda, das variáveis que são objeto do estudo". Segundo Wood e Haber (2001, apud VILELAS, 2009, p. 287) "os questionários são instrumentos de registro escrito e planejados para pesquisar dados dos sujeitos, através de questões a respeito de conhecimentos, atitudes, crenças e sentimentos".

O questionário é, portanto, um conjunto estruturado de questões expressas num papel, destinado a explorar a opinião das pessoas a que se dirige, sendo que há os questionários de tipo Livre, Fechado ou Misto. No tipo Livre, o respondente pode responder livremente e como quiser, o Fechado é elaborado sem qualquer maleabilidade, seguindo um plano rígido onde há canalização das reações das pessoas interrogadas para algumas categorias muito fáceis de interpretar. "No questionário misto, há uma combinação das vantagens dos dois tipos anteriores, com vistas à redução dos seus inconvenientes. Neste tipo de inquérito, as questões podem ser fechadas, mas dá-se a possibilidade de a resposta ser livre" (VILELAS, 2009, p. 289).

Desse modo é que se optou, neste estudo, trabalhar com um Questionário Livre, e com questões Abertas, pois Vilelas (2009) relata que as questões abertas podem trazer mais informações, pormenorizada e inesperada, com maior liberdade nas respostas e menor influência do inquiridor.

Foram distribuídos 10 questionários para professoras regulares, tanto de escola privada quanto de escola pública. Metade das professoras (5) optou em aderir à pesquisa, respondendo e entregando o questionário para a pesquisadora. Dessas cinco professoras, todas são do sexo feminino, com a faixa etária compreendida entre 25 a 31 anos. As professoras foram identificadas como P1, P2, P3, P4 e P5, para que não 
tenham a identidade revelada. Os questionários foram encaminhados via e-mail e foi dado um prazo de preenchimento do mesmo de 1 semana.

Os dados retirados do questionário foram tabulados para serem analisados qualitativamente, por meio da análise de conteúdo que segundo Moraes (1999, p. 8)

constitui uma metodologia de pesquisa usada para descrever e interpretar o conteúdo de toda classe de documentos e textos. Essa análise, conduzindo a descrições sistemáticas, qualitativas ou quantitativas, ajuda a reinterpretar as mensagens e a atingir uma compreensão de seus significados num nível que vai além de uma leitura comum.

Dessa forma, os dados coletados dos questionários sobre o contexto do trabalho docente/pedagógico na inclusão escolar dos alunos público-alvo da educação especial foram analisados e estão descritos no tópico a seguir.

\section{Resultados e discussões}

Os resultados apresentados focam os quesitos que estavam contemplados no instrumento metodológico escolhido para direcionar a pesquisa. Para uma melhor explicitação dos dados coletados, os mesmos foram tabulados e organizados em quadros que serão descritos a seguir:

Quadro 1: Perfil das professoras participantes

\begin{tabular}{|c|c|c|l|c|c|}
\hline Prof & $\begin{array}{c}\text { Idade } \\
\text { anos }\end{array}$ & Sexo & \multicolumn{1}{c|}{ Cargo } & $\begin{array}{c}\text { Tempo de } \\
\text { atuação }\end{array}$ & $\begin{array}{c}\text { Experiência } \\
\text { Profissional }\end{array}$ \\
\hline P1 & 31 & F & Professora Regular & 6 anos & Agente Educacional \\
\hline P2 & 29 & F & Professora Regular & 3 anos & Nenhuma \\
\hline P3 & 30 & F & Professora Regular & 5 anos e 8 meses & $\begin{array}{c}\text { Outros cargos não } \\
\text { relacionados a } \\
\text { educação. }\end{array}$ \\
\hline P4 & 25 & F & Professora Regular & 5 anos & Professora \\
\hline P5 & 31 & F & Professora Regular & 6 anos & Nenhuma \\
\hline
\end{tabular}

Fonte: Elaboração própria

Com a leitura do quadro, verifica-se que em sua totalidade as participantes deste estudo pertencem ao sexo feminino, com faixa etária compreendida entre 25 e 31 anos, sendo que todas são professoras de classe comum, com tempo de experiência no cargo 
que varia de 3 a 6 anos. Quanto a ter outra experiência profissional, os dados revelaram que há professoras sem experiência anterior, com experiência professoral e como agente educacional e em outros cargos não relacionados à educação.

É interessante relatar que segundo a UNESCO (2004), no Brasil há uma concentração significativa de professoras que estão nas faixas etárias de 26 a 35 anos, sendo importante saber sobre esse dado, considerando que a idade do professor constitui uma das marcas de sua atuação, na medida em que é ao longo da sua carreira que o mesmo vai se constituindo professor.

A seguir no quadro 2, serão apresentados os dados concernentes às informações sobre o local do trabalho das professores participantes.

Quadro 2: Informações sobre local do trabalho das professoras participantes

\begin{tabular}{|c|c|c|c|c|c|}
\hline Prof $^{a}$ & $\begin{array}{l}\text { Instituiçãa } \\
\text { Privada Ou } \\
\text { Pública }\end{array}$ & $\begin{array}{l}\text { Sistema Apostilado ou } \\
\text { Livro Didático }\end{array}$ & $\begin{array}{c}\text { Ano } \\
\text { Escolar } \\
\text { Série que } \\
\text { trabalha }\end{array}$ & $\begin{array}{l}\text { Quantidade de } \\
\text { alunos por turma } \\
\text { que atende e de } \\
\text { aluno incluído. }\end{array}$ & $\begin{array}{l}\text { Carga } \\
\text { Horária }\end{array}$ \\
\hline P1 & $\begin{array}{c}\text { Pública } \\
\text { (municipal) e } \\
\text { Privada }\end{array}$ & $\begin{array}{l}\text { Pública não segue material } \\
\text { didático especifico e a } \\
\text { Privada é sistema apostilado }\end{array}$ & $\begin{array}{l}5^{\text {a }} \text { etapa da } \\
\text { educação } \\
\text { infantil e } 1^{\circ} \\
\text { ano }\end{array}$ & $\begin{array}{l}36 \text { alunos e } 1 \mathrm{de} \\
\text { inclusão }\end{array}$ & $\begin{array}{l}56 \text { horas } \\
\text { semanais }\end{array}$ \\
\hline $\mathrm{P} 2$ & $\begin{array}{l}\text { Pública } \\
\text { (municipal }\end{array}$ & Livros Didáticos & $1^{\circ}$ ano & $\begin{array}{c}18 \text { alunos e } 1 \\
\text { inclusão sem laudo }\end{array}$ & $\begin{array}{l}30 \text { horas } \\
\text { semanais }\end{array}$ \\
\hline P3 & $\begin{array}{c}\text { Pública } \\
\text { (municipal) }\end{array}$ & $\begin{array}{l}\text { Livros Didáticos fornecidos } \\
\text { pelo programa nacional do } \\
\text { governo federal }\end{array}$ & $2^{\circ}$ ano & $\begin{array}{l}26 \text { alunos e no } \\
\text { momento nenhum } \\
\text { de inclusão }\end{array}$ & $\begin{array}{l}33 \text { horas } \\
\text { semanais }\end{array}$ \\
\hline P4 & $\begin{array}{l}\text { Pública } \\
\text { (estadual) e } \\
\text { Privada }\end{array}$ & $\begin{array}{c}\text { A escola pública trabalha } \\
\text { com livros didáticos como } \\
\text { complemento ao material } \\
\text { EMAI e Ler e Escrever e a } \\
\text { escola privada trabalha com } \\
\text { o sistema apostilado do J. } \\
\text { Piaget }\end{array}$ & $5^{\circ}$ e $3^{\circ}$ ano & $\begin{array}{l}47 \text { alunos e } 3 \\
\text { inclusão com } \\
\text { laudo fechado }\end{array}$ & $\begin{array}{l}55 \text { horas } \\
\text { semanais }\end{array}$ \\
\hline P5 & $\begin{array}{c}\text { Pública } \\
\text { (municipal) }\end{array}$ & Sistema apostilado do Sesi & $4^{\circ}$ ano & $\begin{array}{l}24 \text { alunos } 3 \text { de } \\
\text { inclusão }\end{array}$ & $\begin{array}{l}33 \text { horas } \\
\text { semanais }\end{array}$ \\
\hline
\end{tabular}

Fonte: Elaboração própria

Conforme os dados apresentados no quadro 2, três professoras (60\%) informaram que trabalham em escola pública e as outras duas (40\%) trabalham um período na escola pública (uma na municipal e outra na estadual) e outro período na escola privada. Quanto ao tipo de sistema adotado na escola onde as professoras 
trabalham, foi verificado que são utilizados sistema apostilado nas escolas privadas e em uma rede municipal e os livros didáticos são utilizados nas redes municipais e estaduais.

O ano escolar compreendido neste estudo variou da $5^{\text {a }}$ etapa da educação infantil ao $5^{\circ}$ ano do ensino fundamental, faltando contemplar o $2^{\circ}$ ano do ensino fundamental. A quantidade de alunos atendidos pela professora P1 é de 36 alunos e 1 de inclusão, a professora P2 atende a 18 alunos com 1 aluno incluído e a professora P3 atende a 26 alunos e nenhuma inclusão no momento. A professora P4, atende ao todo 47 alunos tendo 3 inclusão com laudo e a professora P5 atende a 24 alunos com 3 alunos incluídos. A carga horária de trabalho das professoras varia de 30 horas a 56 horas semanais.

Esses resultados mostram como a ineficiência no uso do tempo do professor dentro da estrutura escolar prejudica sobremaneira o desempenho docente, pois como é possível um professor que dobra o período de trabalho e atende em média de 36 a 47 alunos por dia, ter tempo hábil para planejar, pesquisar atividades diferenciadas e adequadas para os alunos incluídos? Segundo Oliveira (2014) a ineficiência no uso do tempo do professor significa salário menor para cada hora trabalhada, ou seja, o professor opta por dobrar o período de trabalho em busca de um ganho maior no seu salário, o que compromete um trabalho mais eficaz em sala de aula.

O quadro 3, apresenta os dados relacionados à formação das professoras participantes.

Quadro3: Formação das professoras participantes

\begin{tabular}{|l|c|c|c|c|c|}
\hline Prof. & $\begin{array}{c}\text { Curso } \\
\text { Magistério }\end{array}$ & Graduação & $\begin{array}{c}\text { Instituição } \\
\text { Modalidade }\end{array}$ & $\begin{array}{c}\text { Pós- Graduação } \\
\text { Instituição }\end{array}$ & Cursos Extras \\
\hline P1 & Não & Pedagogia & $\begin{array}{c}\text { Unesp/CAr } \\
\text { Presencial }\end{array}$ & $\begin{array}{c}\text { Sim/Latu Sensu } \\
\text { Psicopedagogia Clinica e } \\
\text { Institucional - UNICEP }\end{array}$ & Não informou \\
\hline P2 & Não & Pedagogia & $\begin{array}{c}\text { Unesp/CAr } \\
\text { Presencial }\end{array}$ & Não & Não informou \\
\hline P3 & Não & Pedagogia & $\begin{array}{c}\text { Unesp/CAr } \\
\text { Presencial }\end{array}$ & Não & $\begin{array}{c}\text { Professora informou que } \\
\text { já fez vários }\end{array}$ \\
\hline P4 & Não & Pedagogia & $\begin{array}{c}\text { Ufscar } \\
\text { Presencial/ } \\
\text { Integral }\end{array}$ & Não & $\begin{array}{c}\text { Pacto/Matemática } \\
\text { (Município) e Todos } \\
\text { Aprendem (Estado) }\end{array}$ \\
\hline P5 & Não & Pedagogia & $\begin{array}{c}\text { Unesp/CAr } \\
\text { Presencial }\end{array}$ & Não & Não informou \\
\hline
\end{tabular}

Fonte: Elaboração própria 
Verificando os dados apresentados no quadro 3, confirma-se que nenhuma professora participante informou que fez o curso de Magistério no antigo Centro Específico de Formação e Aperfeiçoamento do Magistério (CEFAM), sendo que todas são Pedagogas formadas por instituições públicas: quatro $(80 \%)$ cursaram na Universidade Estadual Paulista "Júlio de Mesquita filho", campus de Araraquara e uma (20\%) cursou na Universidade Federal de São Carlos, na modalidade presencial. Somente a professora P1 informou que tem curso de Pós-graduação Lato Sensu em Psicopedagogia Clinica e Institucional. Quanto a cursos extras, somente a professora P3 informou que já fez vários cursos e a professora P4 que relatou que fez o curso do Pacto para o ensino da Matemática no município e o curso Todos aprendem na Secretaria Estadual da Educação.

Conforme visto nos dados acima, nenhuma professora informou que tenha formação ou curso na área da Educação Especial, o que muitas vezes pode significar um entrave para atuação com a inclusão escolar de alunos público-alvo da educação especial, por não saberem fazer uso de recursos diferenciados a fim de possibilitar o desenvolvimento educacional dos alunos.

Dessa forma que Fontes (2009) alerta que vários autores como Mendes (2002), Glat \& Nogueira (2002), Nunes (2003), Beyer (2005), Jesus (2006), entre outros, discutem sobre o despreparo do professor em trabalhar com a diversidade, evidenciando que o tema formação de professores na viabilização da inclusão escolar dos alunos público-alvo da Educação Especial deve ser considerado como uma questão importante e urgente a ser pensada.

\section{Informações Pedagógicas: Percepções do trabalho desenvolvido.}

Nesta etapa do instrumento de coleta de dados, foram tratadas questões sobre percepções das professoras em relação ao trabalho desenvolvido na sala de aula com a inclusão do aluno com deficiência. Segue a descrição dos dados coletados.

\section{Desenvolvimento do trabalho pedagógico com todos os alunos da sala de aula}


A professora P1 relatou que planeja as aulas com antecedência e realiza as adaptações necessárias para o aluno com deficiência. A professora P2 afirmou que "ministro aula da mesma forma para todos, intervindo nas atividades com o aluno com dificuldades". A professora P3 afirma que muitos fatores acabam influenciando no trabalho realizado em sala de aula, sendo que em sala que há inclusão o trabalho acaba tendo influências dos gestores responsáveis pelas políticas públicas, pelos gestores das unidades escolares e pelos professores de Educação Especial. Segundo ela há dois momentos do trabalho pedagógico: "um onde penso sobre o que é esperado para a turma de maneira geral e as adaptações que são necessárias, considerando o nível de desenvolvimento dos alunos, considerando-se não apenas os alunos de inclusão, mas qualquer aluno que tenha um desempenho diferente daquilo que é esperado para determinado momento da aprendizagem" (registro em questionário, outubro de 2015)

Para a professora $\mathrm{P} 4$, o esclarecimento sobre o aluno de inclusão e sobre a compreensão das diferenças no tratamento e nas atividades, faz com que os outros alunos respeitem e auxiliem este aluno no trabalho pedagógico. Com isso "consigo dar andamento às atividades planejadas, dando aula normalmente e auxiliando o aluno incluído a alcançar os objetivos de cada aula”.

Finalizando este item, a P5 relata que o trabalho com os alunos que não possuem deficiência é feito utilizando os livros do sistema apostilado que o município adotou.

Quanto ao trabalho pedagógico realizado em sala de aula comum com aluno incluído o mesmo pode ser considerado importante, pois conforme Veiga-Neto (2001) e Silva (2009) é possível construir a sala de aula como o espaço do encontro, onde as diferenças se transformam em pessoas, onde é possível promover saberes novos para todos. E de uma forma ou outra, algumas dessas professoras estão caminhando para que as salas onde ministram aula se torne um espaço onde todos possam estar.

\section{Como se dá o trabalho pedagógico com o aluno que é público-alvo da Educação Especial.}

A professora P1 atende a um aluno com Paralisia Cerebral, então o trabalho maior que ela desenvolve está na área motora, tanto a coordenação motora fina quanto a grossa, já que o mesmo se desenvolve academicamente igual aos outros alunos. Para a P2 o trabalho com o aluno incluído se dá da mesma maneira que com os demais, só 
necessitando dar "uma ajuda individual para ele nas atividades que apresenta maiores dificuldades".

A professora P3 coloca que é muito difícil o trabalho com o aluno incluído, pois "acho que não conseguimos dar um atendimento adequado quando estamos sozinhos, tanto para desenvolver as atividades quanto para aplicá-las, que é o que acontece na maioria das vezes". A professora completa que ela tenta aplicar as mesmas atividades que são oferecidas aos demais, somente adaptando-as, ou oferece outras atividades que estejam dentro do mesmo contexto e/ou oferece atividades diferenciadas, de acordo com o nível de desenvolvimento do aluno em questão.

As informações obtidas com a professora P4 foram que as atividades são diferenciadas para que os alunos alcancem a aprendizagem dos conceitos. Ela utiliza atividades orais e jogos, e o atendimento na sala de recursos é realizado concomitantemente com o seu, para que a aluna consiga se alfabetizar.

A professora P5 afirmou que as atividades dos alunos com deficiência são "adaptadas, pois eles não conseguem realizar as atividades das apostilas que os demais alunos seguem".

A questão de trabalhar pedagogicamente igual com os alunos incluídos e com os alunos ditos normais pode estar relacionada à concepção que o professor traz sobre a normalização da pessoa com deficiência e seus pares. Segundo Anjos, Andrade e Pereira (2009) a concepção de normalidade pode ser organizada em dois grupos: o que recusa o conceito, questionando a ideia de normalidade e o que assume a existência de uma normalidade entre todos, sendo que para alguns professores, normalidade tem relação com a aceitação pelo outro, fazer coisas comuns, participar, interagir, brincar. Tal naturalização tanto pode contribuir para uma aproximação das diferenças quanto para reduzir as especificidades a uma diferença homogeneizada, não sendo muito distinta, em seus efeitos de sentido, daquela naturalização criada pelos processos segregativos, que atribuía ao indivíduo a responsabilidade pela deficiência.

\section{Qual a principal dificuldade encontrada no trabalho com o aluno incluído}

A professora $\mathrm{P} 1$ relatou sobre a dificuldade voltada para a questão da acessibilidade do aluno, por causa do uso da cadeira de rodas;; faltam rampas e móveis adaptados para uso do aluno. Já a professora P2 relatou que a sua maior dificuldade com 
o aluno foi a questão de manter o mesmo concentrado nas atividades aplicadas em sala de aula.

Para a professora P3, a falta de um trabalho coletivo é a principal dificuldade, pois a mesma afirmou que "incluir um aluno não é trabalho de uma pessoa só. Os agentes educacionais precisam trabalhar em conjunto e muitas vezes, isto não acontece". A professora P4 diz que sua maior dificuldade é saber qual a melhor forma de adaptar as atividades em função da situação apresentada. E para a professora P5, a "maior dificuldade é preparar atividades que realmente vão ajudar no desenvolvimento do aluno", atividades que contemplem suas reais necessidades.

A questão da acessibilidade ainda é conhecida por poucos, embora esteja garantida no artigo $8^{\circ}$ do Decreto $n^{\circ} 5296$ de 02 de dezembro de 2004 que regulamenta as Leis $n^{\circ} 10.048$ de 08 de Novembro de 2000 e nº 10.098 de 19 de dezembro de 2000, ambas sobre Acessibilidade, e trata de condição para utilização com segurança, total ou assistiva, dos espaços, mobiliários e equipamentos urbanos, das edificações, dos serviços de transporte e dos dispositivos, sistemas e meios de comunicação e informação, por pessoa com deficiência ou mobilidade reduzida. Conforme Manzini (2010, p. 286) "é necessário ofertar nas escolas as condições de acessibilidade em: edificações, meios de comunicação e informações e recursos didáticos", mas o que tem se visto é que a legislação não está sendo cumprida, pois se pensarmos se as pessoas tem tido essas possibilidades e direito de fato, veremos que não. Um aluno usuário de cadeiras de rodas consegue utilizar todos os ambientes da escola sem barreiras? Conforme o dado fornecido por uma das professoras verifica-se que não. Outro dado que chama nossa atenção nestas respostas é a denuncia de um trabalho isolado. $\mathrm{O}$ professor na maioria das vezes se sente sozinho, sem interlocução para discutir seu trabalho pedagógico em um contexto em que as diferenças dos alunos requerem ações também diferenciadas. O estabelecimento de parcerias e o trabalho colaborativo são elementos fundamentais para a efetivação de um trabalho inclusivo.

\section{Realização de adaptação para o aluno incluído, quem pensa essa adaptação?}

A professora P1 relatou que ela mesma pensa as adaptações e as coloca em prática. A Professora P2 informou que não realiza adaptações para o aluno incluído. Para a professora P3, as adaptações dependem da necessidade do aluno e as mesmas 
deveriam ser pensadas em um trabalho coletivo, por todos: professora regular, professora de Educação Especial e demais profissionais que atendam o aluno incluído. Ela informa que acaba realizando as adaptações individualmente, sem muitas informações como devem ser feitas. O máximo que ela conseguiu com as professoras especialistas foram poucas orientações, mas não um auxílio para a elaboração das atividades e ela sente falta desse apoio.

Finalizando sobre este tópico, a professora P4 e P5 informaram que as atividades sempre que possível são adaptadas ao conteúdo que está sendo estudado, principalmente aos de Matemática e Língua Portuguesa, sendo preparadas por elas mesmas.

No paradigma da Inclusão Escolar, são previstas algumas adequações necessárias para atender o aluno com deficiência: adequações nas estruturas arquitetônicas, meio de transporte, no ambiente e as Adaptações Curriculares, que melhor responde às necessidades do alunado. Adaptações curriculares segundo Oliveira e Machado (2007, p. 45) são "modificações realizadas no planejamento, nos objetivos da escola, nos conteúdos, nas atividades, nas estratégias de aplicação desse conteúdo e da avaliação, no currículo como um todo ou um aspecto dele". As mesmas podem ser divididas em grande porte (realizadas em âmbito político e administrativo) e de pequeno porte (são realizadas nas escolas e dentro das salas de aula).

Para que as professoras possam desenvolver adaptação das atividades, seria necessário que as mesmas pudessem participar de curso de formação continuada na área, para suprir o currículo de sua formação pedagógica que não as preparou para atender as particularidades de todos os alunos (OLIVEIRA E MACHADO, 2007). Mais uma vez, a questão da colaboração aparece como um elemento necessário para o trabalho pedagógico. A falta de interação entre professores comuns e especializados, entre professores e coordenadores/gestores, entre escola e instituições de apoio (escolas especiais, centros de apoio, universidades, entre outros), comprometem o trabalho, que desta maneira poderia ser bem mais produtivo.

Adaptações de acesso ao currículo e pedagógico realizados na escola e na sala de aula.

As informações trazidas pela professora P1 alertam que não houve modificação alguma na infraestrutura da escola, sendo que as adaptações pedagógicas foram 
realizadas sem auxilio ou orientação da coordenação/direção escolar a não ser quanto ao uso da ampliação das linhas e tamanhos das letras para o aluno que apresenta Paralisia Cerebral/baixa visão. Como a professora P2 já informou que não realiza adaptação alguma para o aluno incluído na sala de aula comum, a mesma afirmou novamente que não há adaptações, somente que o aluno é atendido uma vez por semana pela professora especialista.

A professora P3 respondeu que não dá para dizer ao certo sobre as adaptações, pois as mesmas vão depender das necessidades apresentadas pelo aluno incluído. A professora $\mathrm{P} 4$ afirmou que os alunos têm uma série de direitos que são cumpridos tanto na escola pública quanto na escola privada, sendo que "as atividades são diferenciadas seguindo o mesmo tema das atividades dos outros alunos, tendo adaptação de avaliação para os alunos de inclusão escolar”.

A professora P5 informou que as professoras especialistas do Atendimento Educacional Especializado (A.E.E.) preparam o currículo adaptado e as professoras regulares preparam as atividades baseadas nesse currículo.

A questão das adaptações curriculares de pequeno porte é uma incógnita que cerca o trabalho docente das professoras quanto ao planejamento e desenvolvimento das práticas em sala de aula. Como as professoras não têm informações necessárias (falta formação nessa área para os professores) sobre as adaptações curriculares, as mesmas tentam seguir o que acham ser o certo para fazer com os alunos incluídos, trazendo atividades diferenciadas ou até mesmo aplicam para todos os alunos as mesmas atividades alegando que todos os alunos são tratados igualmente (questão de homogeneidade), não se baseando na questão da equidade que deve existir em sala de aula.

\section{Principal solicitação da professora regular para a professora especialista}

Na escola privada que a professora P1 trabalha, não há professoras especialistas trabalhando. O aluno incluído é atendido na Associação de Apoio a Criança Deficiente (AACD) de São José do Rio Preto e que a psicopedagoga desta instituição envia bilhetes à professora regular dando sugestões, críticas ou elogios referentes às atividades desenvolvidas em sala de aula. A professora P2 não mantém contato com a professora especialista. 
A professora P3 acredita que a professora especialista deve estar envolvida em todos os processos: avaliação, adaptação curricular, elaboração de atividades e eventualmente participar também dos processos de ensino realizados na sala regular. A professora não informou se isso vem acontecendo ou não no seu caso.

A informação trazida pela P4 é que a sua maior solicitação para com a professora especialista é quanto a alfabetização e as noções básicas de matemática, pois "com o restante da sala (alunos) o ambiente não favorece estas aprendizagens".

A professora P5 relatou que sempre conversa com a especialista sobre o desenvolvimento dos alunos incluídos.

Os professores precisam aprender a trabalhar em colaboração, pois uma forma para que a Educação Inclusiva realmente aconteça é por meio do Ensino Colaborativo/ Bidocência, que pode ser definido como ação de parceria entre dois docentes, sendo um destes, especialista nas diversas áreas da educação especial/ inclusiva. Perez (2009, apud BÜRKLE, 2010, p.113) relata que "a cultura colaborativa parece ser a chave para a mudança na cultura escolar e, consequentemente, de novos valores, saberes que transformem a escola num espaço de fato inclusivo".

\section{Interações ou discriminações entre alunos incluídos ou não.}

A professora P1 relatou que o aluno incluído é muito querido por todos, havendo disputa entre os alunos para ver quem vai brincar com ele. Ela afirmou ainda que a sala ficou mais humana depois da inclusão do aluno com deficiência. A professora P2 afirmou que o aluno é tratado como todos, que não há nem diferenciação e nem exclusão.

A professora P3 acredita que as duas coisas acabam acontecendo em sala de aula, pois os alunos querem entender as diferenças entre eles. Há alunos que desenvolveram uma postura de acolhimento e suporte, criando vínculos de amizade, mas há alunos que se distanciam e discriminam, criando posturas discriminatórias, precisando ser trabalhado essas posturas com os mesmos.

Para a professora $\mathrm{P} 4$, os alunos se mostram compreensivos e prontos para ajudar, mas as vezes até ocorrem piadas e brincadeiras de mau gosto, "mas não tanto por ser inclusão, mas por serem crianças que as vezes entram em atrito”. 
A professora P5 afirmou que os demais alunos entendem que os alunos incluídos têm algumas limitações e não expressam atitudes discriminatórias.

Os resultados apresentados revelam que segundo as professoras ainda se encontram situações de discriminações na sala de aula, o que sugere a necessidade de um trabalho da escola no sentido de valorização das diferenças e de criação de um espaço acolhedor para todos. No entanto, as respostas também demonstram que as interações entre os alunos incluídos e o restante dos alunos vêm aumentando e se firmando.

\section{Percepção da professora regular quanto à estadia do aluno com deficiência em sala de aula regular.}

A professora P1 tem uma percepção que a inclusão desse aluno em sala de aula traz ganhos para o próprio aluno e para os demais, pois esse convívio possibilita a todos conviver com a diferença. A professora $\mathrm{P} 2$ relatou perceber que o aluno se desenvolveu bastante no decorrer do ano, embora avalie que ele ainda precisa desenvolver a coordenação motora fina/grossa.

A percepção da professora P3 é que a mesma acredita que a estadia em sala regular influencia positivamente o desenvolvimento acadêmico e social do aluno incluído, mesmo com todas as dificuldades que há na sala regular ainda. "é preciso trabalhar para superar as dificuldades e assim melhorar o atendimento ao aluno incluído".

A professora P4 apresentou a percepção que essa estadia é importante, apesar de que há alguns casos complicados em ser mantido em sala regular. A professora afirmou ainda que esse convívio entre os diferentes traz ganho no desenvolvimento de novas habilidades e no aspecto social também: "cada nova aquisição é um ganho para o aluno especial, desde aprender a esperar a vez para falar até conteúdos mais complexos".

Quanto a percepção da professora P5, está relacionado ao fato que o aluno com deficiência incluído em sala de aula regular acaba apresentando grandes avanços em suas aprendizagens acadêmicas e também nas suas relações sociais.

Os resultados quanto à percepção das professoras sobre a estadia do aluno incluído em sala de aula comum é que essa inserção traz inúmeros ganhos acadêmicos e 
sobretudo sociais, o que corrobora com várias pesquisas que estudam qual é o melhor lugar para se ensinar o aluno público-alvo da educação especial, desde que com o uso de todos os suportes necessários (MENDES, 2010; BAPTISTA, 2011; KASSAR, 2011).

\section{Considerações e/ou sugestões das professoras regulares quanto a aspectos ainda não tratados no estudo.}

A professora P1 afirmou que a Inclusão funciona somente quando há o interesse e a boa vontade do docente em procurar informações, adaptar, incentivar e acolher o aluno. Quem conduz toda a situação é o docente, podendo facilitar ou dificultar a permanência de qualquer aluno, seja ele "portador" ou não de alguma deficiência (grifo meu). A "ajuda e interesse da escola pode auxiliar e dar mais ferramentas a este para executar um trabalho melhor estruturado". As professoras P2, P3 e P5, não comentaram nada além do já descrito no estudo.

A professora P4 considerou que há necessidade de maior atenção para os casos de inclusão, pois muitas vezes acabam ficando em sala de aula, mas não são de fato incluídos. A professora afirma que esta exclusão é na verdade o pior tipo, pois se mascara como algo bom e até que uma atitude seja tomada, a trajetória escolar da criança pode se tornar um fracasso escolar; "também acho importante enfatizar sempre cada conquista do aluno especial, que embora não caminhe no mesmo ritmo que a turma, está sempre avançando, aprendendo coisas novas, etc”.

\section{Conclusões}

Ao finalizar este artigo no qual foi proposto verificar como as professoras estão conseguindo desenvolver o trabalho docente/pedagógico com alunos incluídos na sala de aula comum, foi possível verificar como a formação docente é extremamente importante para que o professor possa atender novas demandas que envolvem o trabalho com grupos diferenciados de alunos.

Foi importante de fato verificar que as professoras participantes não participaram de qualquer curso voltado para a área da Educação Especial e estão trabalhando com alunos incluídos. Essas professoras não apresentam conhecimento 
suficiente para poder pesquisar, planejar e escolher atividades que possam ser eficazes no processo de ensino aprendizagem dos seus alunos público-alvo da educação especial. Mas pode-se verificar que a maioria dessas professoras está tentando adaptar atividades, tentando fazer um trabalho diferenciado e há questionamentos na falta de apoio que as mesmas sentem por parte das professoras especialistas.

Percebe-se claramente que as condições da estrutura escolar, com a ineficiência no uso do tempo do professor, com a própria concepção do professor quanto aos alunos incluídos, com salas numerosas de alunos, com a falta de acessibilidade, com a falta de apoio dos demais profissionais da educação, com decisões externas às salas de aula, com a falta de formação adequada para o professorado, restringem em muito as práticas pedagógicas e o trabalho em geral que são voltados para a inclusão dos alunos com deficiências/impedimentos educacionais.

Dessa forma, que investigar e considerar os achados quanto ao trabalho desenvolvido em salas de aula com alunos incluídos é relevante para se pensar como a parte legislativa, com todas suas recomendações, pode fazer com que as mudanças efetivadas nos documentos legais possam ser aplicadas e desenvolvidas na prática de sala de aula nas escolas reais que temos em nosso país.

Para finalizar, destaca-se que esse trabalho possibilitou verificar que apesar das muitas dificuldades no contexto escolar, algumas professoras consideraram que a chave para a inclusão escolar está depositada no docente, mas que o interesse da escola como um todo é que pode trazer ferramentas para um trabalho mais estruturado e eficaz no dia a dia com os alunos com deficiência ou não.

\section{Referências}

ANJOS, H. P.; ANDRADE, E. P.; PEREIRA, M. R. A inclusão escolar do ponto de vista dos professores: o processo de constituição de um discurso. Revista Brasileira de Educação, Rio de Janeiro, vol.14 n.40, p. 116-129, jan./apr. 2009. Disponível em: <http://dx.doi.org/10.1590/S1413-24782009000100010>. Acesso em: 03 de jan. de 2016.

BAPTISTA, C. R. Ação Pedagógica e Educação Especial: A sala de recursos como prioridade na oferta de serviços especializados. Rev. bras. educ. espec. Marília, vol.17, n. spe1, p. 59-76. ISSN 1413-6538. maio/ago. 2011.

BEYER, H. O. Inclusão e avaliação na escola de alunos com necessidades educacionais especiais. Porto alegre: Mediação, 2005. 
BRASIL. Ministério da Educação. Decreto no 5.296, de 02 de dezembro de 2004. Regulamenta as Leis $\mathrm{n}^{\circ} 10.048 / 2000$ e $\mathrm{n}^{\circ} 10.098 / 2000$. Presidência da República. Casa Civil. Disponível em: <http://www.planalto.gov.br/ccivil_03/_ato20042006/2004/decreto/d5296.htm>. Acessado em: 05 de fev. de 2016.

\section{Ministério da Educação. Política Nacional de Educação Especial na Perspectiva da Inclusão Escolar, Brasília, 2008. Disponível em:<portal.mec.gov.br/seesp/arquivos/pdf/política.pdf $>$. Acesso em: $05 \mathrm{de}$ dez. de 2015.}

INEP. Censo Escolar. 2013. Disponível em: <http://portal.mec.gov.br/buscageral/212-noticias/educacao-superior-1690610854/20777-censo-indica-crescimento-de38-nas-matriculas-e-total-de-alunos-chega-a-73-milhoes-em-2013>. Acesso em: 03 de jan. de 2016.

. Coordenadoria Nacional para a Integração da Pessoa Portadora de Deficiência (CORDE). Declaração de Salamanca e Linha de Ação sobre Necessidades Educativas Especiais. Brasília, 1994.

BÜRKLE, T. S. A sala de recurso como suporte à educação inclusiva no Município do Rio de Janeiro: das propostas legais à prática cotidiana. 146f. (Mestrado em Educação) Centro de Educação e Humanidades, Universidade do Estado do Rio de Janeiro, Rio de Janeiro,2010. Disponível: <www.eduinclusivapesquerj.pro.br/teses/teses.asp>. .Acesso em: 18 de dez. de 2015.

DECLARAÇÃO Mundial sobre educação para todos . Plano de ação para satisfazer as necessidades básicas de aprendizagem. Tailândia, 1990. Disponível em: <http://www.dhnet.org.br/direitos/sip/onu/educar/todos.htm>. Acesso em: 20 de nov. de 2015 .

FONTES, R. S. Ensino colaborativo: uma proposta de educação inclusiva. Araraquara, SP: Junqueira \& Marin, 2009.

GLAT, R.; NOGUEIRA, M. L. de L. Políticas Educacionais e a formação de professores para a Educação Inclusiva no Brasil. Revista Integração, Brasilia, v. 14, n. 24, p. 22-27, 2002.

JESUS, D. M. Formação continuada: constituindo um diálogo entre teoria, prática, pesquisa e a educação inclusiva. In: JESUS, D. M.; BAPTISTA, C. R.; VICTOR, S. L. (org). Pesquisa e Educação Especial: mapeando produções. Vitória: EDUFES, 2006.

KASSAR, M. C. M., Percursos da constituição de uma política brasileira de Educação Especial Inclusiva. Rev. bras. educ. espec. Marília, vol.17, n.spe1, p. 41-58. mai/ago. 2011.

MANZINI, E. J. Acessibilidade: um aporte da legislação para o aprofundamento do tema na área de educação. In: BAPTISTA, C. R.; CAIADO, K. R. M.; JESUS, D. M. Educação especial: diálogo e pluralidade. 2. ed. Porto Alegre: Mediação, 2010. 
MAZZOTTA, M. J. S. Educação Especial no Brasil: histórias e políticas públicas. $6^{\text {a }}$ ed. - São Paulo: Cortez, 2011.

MENDES, E. G. Desafios atuais na formação do professor de educação especial. In: MEC, Secretaria de Educação Especial. Revista Integração, Brasília, n. 14, v. 24, p. 12-17, 2002.

MENDES, E. G.; ALMEIDA, M. A. Das margens ao centro: perspectivas para as políticas e práticas educacionais no contexto da educação especial inclusiva. Araraquara, SP: Junqueira\&Marin, 2010.

MORAES, R. Análise de Conteúdo. Revista Educação. Porto Alegre, v. 22, n 37, p 732, $1999 . \quad$ Disponível em: <cliente.argo.com.br/ mgos/analise_de_conteudo_moraes.html>. Acesso em 05 de jan. de 2016

NUNES SOBRINHO, F. de P. (org) Inclusão Educacional: pesquisa e interfaces. Rio de Janeiro: Livre Expressão, 2003.

OLIVEIRA. J. B. A. O Brasil em alerta máximo. Valor Econômico, 18 fev. 2014 Disponível $<$ http://www.informacoesmunicipais.com.br/?pagina=detalhe_noticia\&noticia_id=4393 4>. Acesso em: 21 de dez. de 2015.

OLIVEIRA, E.; MACHADO, K. S. Adaptações curriculares: caminho para uma educação inclusiva. IN: GLAT, R. (org.). Educação inclusiva: cultura e cotidiano escolar. Rio de Janeiro: 7letras, 2007.

PÉREZ, V. M. O. Cultura escolar y mejora de la educación. Disponível em:

<http://www.lasalle.edu.mx/diplo_inst_las/docs_diplo/2domodulo/cultura_escolar_mejo ra.pdf>. Acesso em: 30 de set. de 2009.

SILVA, T. T. A produção social da identidade e da diferença. In: SILVA, T.T.(org.). Identidade e diferença: a perspectiva dos estudos culturais. $9^{a}$ edição. Petrópolis, RJ: Vozes, 2009.

UNESCO. O perfil dos professores brasileiros: o que fazem o que pensam o que almejam. Pesquisa Nacional. São Paulo: Moderna, 2004.

VEIGA-NETO, A. Incluir para excluir. In: LARROSA, Jorge; SKLIAR, Carlos (orgs.). Habitantes de Babel: políticas e poéticas da diferença. Belo Horizonte: Autêntica, 2001.

VILELAS, J. Investigação: O processo de Construção do Conhecimento. Lisboa: Edições Sílabo, 2009.

WOOD, G; HABER, J. Pesquisa em Enfermagem: Métodos, Avaliação Crítica e Utilização. $4^{\text {a }}$ Ed. Rio de Janeiro: Guanabara Koogan, 2001. 


\section{Como referenciar este artigo}

SILVA, Suzana Sirlene da.; CARNEIRO, Relma Urel Carbone. Inclusão escolar de alunos público-alvo da educação especial: como se dá o trabalho pedagógico do professor no ensino fundamental I?. Revista Ibero-Americana de Estudos em Educação, v. 11, n. esp. 2, p.935-955, 2016. Disponível em: <https://dx.doi.org/10.21723/riaee.v11.esp2.p935-955>. E-ISSN: 1982-5587.

\section{Sobre os autores}

i Aluna especial. UNESP - Universidade Estadual Paulista. Faculdade de Ciências e Letras - Pósgraduação em Educação Escolar. Araraquara - SP - Brasil. 14800-901 - suzana.sirlene @ yahoo.com.br ii UNESP - Universidade Estadual Paulista. Faculdade de Ciências e Letras - Pós-graduação em Educação Escolar. Araraquara - SP - Brasil. 14800-901 - relmaurel@ fclar.unesp.br 